\title{
How well can we predict earthquakes?
}

ANDREW MICHAEL

How well can we predict earthquakes? As suggested in Ian Main's introduction to this forum, we can easily predict the behaviour of populations of earthquakes and we clearly cannot completely predict the behaviour of individual earthquakes. But where is the boundary between the easy and the impossible? In search of this boundary let us take a tour through Ian Main's four levels of earthquake prediction.

Level 1, time-independent hazard estimation, clearly shows that we can predict the behaviour of earthquake populations. Here we seek spatially varying estimates of average earthquake rates. Such calculations are common and the results are widely used. To argue otherwise you must believe in equal earthquake hazards for both California and Britain.

Time-dependent earthquake hazard estimation, level 2 in Ian Main's scheme, can be divided into two parts. Temporal and spatial earthquake clustering, which I shall denote as level $2 \mathrm{a}$, can lead to some definite improvements over the time-independent estimates. Aftershocks are a major part of any earthquake catalogue and the largest ones are capable of doing additional damage. Probabilistic estimates of aftershock rates can be used to aid emergency response and recovery operations after damaging earthquakes 1,2 . Although predicting aftershocks is an admirable goal, by definition it does not include predicting the largest and most damaging earthquakes.

Recognizing foreshocks would allow us to predict these more important events. But no one has been able to identify which earthquakes are foreshocks. This has limited us to statistical analyses in which we probabilistically estimate the odds that an earthquake is a foreshock $\underline{3}$ or treat each earthquake as a main shock and allow for the possibility that one of its aftershocks might be larger ${ }^{1,2}$. In both cases, the probabilities that any earthquake will be followed by a larger event are only a few per cent over the first several days. There might also be significant uncertainties in these probabilities ${ }^{4}$. Understanding earthquake clustering in terms of stress transfer and rate and state friction laws $\frac{5-7}{2}$ might allow us to place these statistical models on a firmer physical footing, but this will not necessarily reduce these uncertainties.

Earthquake clustering is now a routine time-dependent hazard estimation tool in California. Joint foreshock and aftershock probabilities are automatically released by the United States Geological Survey and the State of California after earthquakes over magnitude 5. But does level $2 \mathrm{a}$ let us predict the behaviour of individual earthquakes or merely the behaviour of a population? Predictions based on aftershocks can be fulfilled by a variety of possible events, so they predict the behaviour of a population of earthquakes. In contrast, statistical models of foreshocks target a specific main shock $\frac{3,4}{}$. But actually writing a definition for a single earthquake is quite difficult 4 and so at best these are predictions for one of a small population. Also, given the long time between main shocks, it is difficult to test these predictions of individual events or small populations. The other choice is to do a test over a broad area but then we are really testing the behaviour of the population.

The second part of level 2 continues with the prediction of specific events by using the concept of an earthquake cycle based on the elastic rebound theory ${ }^{8}$. The use of this cycle, which I shall refer to as level $2 b$, led from plate tectonics through seismic gaps and on to time-dependent hazard analysis based on a probabilistic model of the time between earthquakes on a fault segment. To achieve level 1 we need only know the average rate of 
earthquakes in a region. To achieve level $2 \mathrm{~b}$ we must assign those rates to specific fault segments, determine the date of the last event on each fault segment, and choose an earthquake recurrence model. Determining the history of earthquakes on a fault segment is especially difficult in areas such as California, where the historic record is short compared with the average time between major earthquakes. It is also difficult in areas in which the historic record is longer. Although we might know when past earthquakes occurred, we might not know on which fault they occurred. Palaeoseismology, with fault trenches and tree ring studies, attempts to address these questions, but its success varies depending on local conditions.

A few consensus reports have been issued that include time-dependent hazard estimates for California, 9 ; ; an update to the estimates for Northern California is currently under way. Although these analyses attempt to predict individual model events, there is so much uncertainty in the individual predictions that the results are presented as a probabilistic sum over many models. A further problem with level $2 \mathrm{~b}$ is that these predictions might be impossible to test during our lifetimes. Thus, our faith in these predictions relies on our ability to test the components that went into them and our faith in the 'experts' who must make somewhat arbitrary choices when assembling these components. Although the quality of these predictions is debatable, their impact is clearer. Widespread release of earthquake hazards estimates in the San Francisco Bay area have led businesses and governments to spend hundreds of millions on earthquake preparedness $\underline{11}$.

Level 3, the use of precursors, could lead to the prediction of either individual events or the behaviour of the population depending on how large an area the precursors cover. Given that years of effort have led to no widely accepted precursors, perhaps there are no valid earthquake precursors. Or have our efforts been too weak to find them? Although Ian Main asserts that the effort to find precursors has been enormous, it has used only a few per cent of the US earthquake research budget. This limited effort has allowed a wide variety of dense instrumentation to be installed in very few areas, and these areas have not yet experienced a large event $\frac{12,13}{}$. Although the level of effort must be considered against other seismological and societal goals, it is impossible to rule out the existence of precursors on the basis of a lack of observations.

Another option is to show that there cannot be any valid earthquake precursors because the system is simply too chaotic. This would also rule out level 4: the deterministic prediction of individual events. For instance, if when an earthquake begins there is no way of suggesting how large it will become, prediction will be very difficult. Laboratory faults display a slow nucleation process and some recent work suggests a slow ${ }^{14}$, magnitude-proportional 15 nucleation process for real faults, but this remains controversia 16,17 . Other fruitful topics for further research include understanding the frictional behaviour of faults and why they are so much weaker than simple laboratory models $\frac{18,19}{}$. The predictability of the weakening mechanism might affect our view of how predictable the entire system is. For instance, opening-mode vibrations ${ }^{20}$ might be more predictable than the collapse of high-pore-fluid compartments ${ }^{21,22}$. Until we understand better the basic processes of real faults it is too early to say that we will not improve on our current predictive capability. And our knowledge might improve with new observations such as those made in deep drill holes ${ }^{24}$.

In conclusion, scientists are now making societally useful predictions based on both the behaviour of the population of earthquakes and of individual events, although these predictions are best posed in terms of at least small populations. Progress in this field might be difficult but we should heed Sir Peter Medawar's advice 25 : "No kind of prediction is more obviously mistaken or more dramatically falsified than that which declares that something which is possible in principle (that is, which does not flout some established scientific law) will never or can never happen." 


\section{References}

1. Reasenberg, P.A. \& Jones, L.M. California aftershock hazard forecasts. Science . 247, 345-346 (1990)

2. Reasenberg, P.A. \& Jones, L.M. Earthquake hazard after a mainshock in California. Science 243, 1173-1176 (1989)

3. Agnew, D.C. \& Jones, L.M. Prediction probabilities from foreshocks. J. Geophys. Res. 96, 11959-11971 (1991)

4. Michael, A.J. \& Jones, L.M. Seismicity alert probabilities at Parkfield, California, revisited. Bull. Seism. Soc. Am. 87, 117-130 (1998).

5. Dieterich, J. A constitutive law for rate of earthquake production and its application to earthquake clustering. J. Geophys. Res. 99, 2601-2618 (1994).

6. King, G.C.P., Stein, R.S. \& Lin, J. Static stress changes and the triggering of earthquakes: The 1992 Landers, California, earthquake sequence. Bull. Seism. Soc. Am. 84, 935-953 (1994)

7. Stein, R.S., King, G.C.P. \& Lin, J. Stress triggering of the $1994 M=6.7$ Northridge, California, earthquake by its predecessors. Science $\mathbf{2 6 5}$, 1432-1435 (1994)

8. Reid, H.F. The California earthquake of April 18, 1906; the mechanics of the earthquake, Vol. 2, 192 (Carnegie Inst. Wash. Pub. 87, 1910)

9. Working Group on California Earthquake Probabilities. Probabilities of large earthquakes occurring in California on the San Andreas fault. (U.S. Geol. Survey Open-File Rep. 88-398, 1988)

10. Working Group on California Earthquake Probabilities. Probabilities of large earthquakes in the San Francisco Bay region, California. (U.S. Geol. Survey Circular 1053, 1990)

11. Bakun, W.H. Pay a little now, or a lot later. (U.S. Geol. Survey Fact Sheet 169-95, 1995)

12. Bakun, W.H. \& Lindh, A.G. The Parkfield, California, earthquake prediction experiment. Science 229, 619-624 (1985)

13. Roeloffs, E.A. \& Langbein, J. The earthquake prediction experiment at Parkfield, California. Rev. Geophys. 32, 315-336 (1994)

14. Iio, Y. Slow initial phase of the P-wave velocity pulse generated by microearthquakes. Geophys. Res. Lett. 19, 477-480 (1992)

15. Ellsworth, W.L. \& Beroza, G.C. Seismic evidence for an earthquake nucleation phase. Science 268, 851-855 (1995)

16. Mori, J.J. \& Kanamori, H. Initial rupture of earthquakes in the 1995 Ridgecrest, California sequence. Geophys. Res. Lett. 23, 2437-2440 (1996)

17. Ellsworth, W.L. \& Beroza, G.C. Observation of the seismic nucleation phase in the Ridgecrest, California, earthquake sequence. Geophys. Res. Lett. 25, 401-404 (1998)

18. Brune, J.N., Henyey, T.L. \& Roy, R.F. Heat flow, stress, and rate of slip along the San Andreas fault, California. J. Geophys. Res. 74, 3821-3827 (1969)

19. Lachenbruch, A.H. \& Sass, J.H. Heat flow and energetics of the San Andreas fault zone: Magnitude of deviatoric stresses in the Earth's crust and uppermost mantle. J. Geophys. Res. 85, 6185-6222 (1980)

20. Anooshehpoor, A. \& Brune, J.N. Frictional heat generation and seismic radiation in a foam rubber model of earthquakes: Faulting, friction, and earthquake mechanics; Part 1. Pure Appl. Geophys. 142, 735-747 (1994)

21. Rice, J.R. in Fault Mechanics and Transport Properties in Rocks (eds. Evans, B. \& Wong, T.-F.) 475-503 (Academic, 1992)

22. Byerlee, J. Friction, overpressure and fault normal compression. Geophys. Res. Lett. 17, 2109-2112 (1990)

23. Byerlee, J. Model for episodic flow of high pressure water in fault zones before earthquakes. Geology 21, 303-306 (1993)

24. Hickman, S., Zoback, M., Younker, Y. \& Ellsworth, W. Deep scientific drilling in the San Andreas fault zone. Eos 75, 137-142 (1994) 
25. Medawar, P. B. Pluto's Republic (Oxford Univ. Press, London, 1982)

Nature@ Macmillan Publishers Ltd 1999 Registered No. 785998 England. 